\title{
Limits of Level 3 Fair Value Measurement: Based on Conceptual Framework
}

\author{
Nobuhito Ochi \\ Shobi University, Saitama, Japan
}

\begin{abstract}
The IASB stated that in the review of the conceptual framework, if measurement uncertainty is very high, a measurement basis different from fair value may provide more appropriate information. Level 3 fair value measurements are inappropriate for areas (called "Level 4" by the author) in which models are not formulated and that have material uncertainty in measurement. The purpose of this paper is to elucidate "measurement uncertainty", which impacts "faithful representation" in fair value measurement, from the perspective of "verifiability". To do so, it will employ a conceptual examination of the limits of Level 3 fair value measurement based on IFRS 13 (Fair Value Measurement). While taking into consideration recent discussions on reviewing conceptual framework, the author will reorganize the conceptual categories of verifiability (i.e., clarification of the "reasonable verifiability" categories) to underpin the fact that material uncertainties in measurement have obstructed constructing faithful representation. In addition, the author will discuss the problem that the dichotomy of direct and indirect found in IASB is not accurate enough to fully understand the concept of verifiability. In this context, the author will also suggest that the concept of verifiability, reorganized through "reasonable verifiability", can satisfy the requirements for constructing faithful representation.
\end{abstract}

Keywords: level 3 fair value measurement, faithful representation, measurement uncertainty, verifiability

\section{Introduction}

The process of revision of IAS 39 (Financial Instruments: Recognition and Measurement) ultimately was completed with the publication of IFRS 9 (Financial Instruments) in July 2014. Calling for simplification of classification and measurement based on amortized costs and fair value in accordance with more objective standards such as business models and other matters, it does not establish traditional measurement categories based on reliability. However, in connection with review of the conceptual framework, the IASB clearly proposed the concept of "measurement uncertainty" for matters such as unobservable inputs, and in the exposure draft (IASB, 2015) it stated that "measurement uncertainty" could serve in a trade-off function vis-a-vis relevance. Later, in the May 2016 meeting of the IASB board, a tentative decision was made, reflecting comments on the exposure draft that measurement uncertainty was a factor impacting faithful representation rather than relevance (ASBJ, 2016, p. 11).

The purpose of this paper is to elucidate "measurement uncertainty", which impacts "faithful representation" in fair value measurement, from the perspective of "verifiability". To do so, it will employ a conceptual examination of the limits of Level 3 fair value measurement based on IFRS 13 (Fair Value Measurement). Below,

Nobuhito Ochi, Professor, Faculty of Policy Management, Shobi University. Email: n-ochi@s.shobi-u.ac.jp. 
this paper first will discuss the limits of Level 3 fair value measurement using models, from the perspective of reliability. Next, in connection with a review of the conceptual framework, it will consider the relationship between "faithful representation" and "measurement uncertainty" and then, through considering a reconstruction of the conceptual category of "verifiability" (clarifying the category of "reasonable verifiability"), it will develop a conceptual grounding for the material uncertainty of measurement lacking in "reasonable verifiability" along with discussing how the concept of "verifiability", including "reasonable verifiability", could serve as a fundamental constituent element of "faithful representation".

\section{Fair Value Measurement and Reliability in Financial Investment}

\section{Fair Value Measurement in the IFRS}

IFRS 13, which comprehensively covers measurement and disclosure of fair value, describes "fair value" as an exit value that would be paid as the price received or liabilities transferred in sale of an asset under conditions of orderly trading among market participants on the date of measurement. In measuring this value, the characteristics of assets and liabilities taken into consideration by market participants are considered and in addition to the assumption that they are not based on entity-specific methods of use or plans, the concept is employed of the fair value hierarchy, in which inputs used in the valuation method employed in the measurement are prioritized. However, IFRS 13 does not introduce new rules on the kinds of cases in which fair value measurement is required or accepted.

While financial instruments make up a central part of the scope of applicability of fair value, IFRS 9 employs a method of classification based on "business model conditions" (how the entity manages financial instruments) and "cash flow conditions” (contractual cash-flow characteristics of financial instruments) (IFRS 9, Section 4.1). They are classified into three categories based on amortized value and fair value in accordance with their satisfaction of these conditions (see Table 1). IFRS 9 does not include threshold values for reliability, and for assets such as unquoted equity instruments as well, for which measurement at the cost of purchase is acceptable under IAS 39 from the perspective of reliability of measurement, in principle fair value measurement is employed, considering these to be financial instruments that do not satisfy the cash flow conditions.

Table 1

Classification and Measurement of Financial Instruments in IFRS 9

\begin{tabular}{|c|c|c|c|}
\hline & & \multicolumn{2}{|c|}{ Contractual cash flow characteristics } \\
\hline & & Principle and interest only & Other than at left \\
\hline \multirow{3}{*}{$\begin{array}{l}\text { Business } \\
\text { model }\end{array}$} & Contractual recovery of cash flow & (1) Measurement of amortized cost & \multirow{3}{*}{$\begin{array}{l}\text { (3) Fair value measurement through net } \\
\text { income/loss* }\end{array}$} \\
\hline & $\begin{array}{l}\text { Contractual recovery of cash flow } \\
\text { and sale }\end{array}$ & $\begin{array}{l}\text { (2) Fair value measurement through other } \\
\text { comprehensive income }\end{array}$ & \\
\hline & Other than above & $\begin{array}{l}\text { (3) Fair value measurement through net } \\
\text { income/loss }\end{array}$ & \\
\hline
\end{tabular}

Notes. Shaded areas are subject to fair value measurement. *: For equity financial instruments held for purposes other than sale, fluctuations in fair value may be chosen as "other comprehensive income".

\section{Limits of Level 3 Fair Value Measurement in Financial Investment}

Under the IASB conceptual framework, "reliability" was replaced by "faithful representation" as one of the fundamental qualitative characteristics of accounting information, but common understanding of the characteristics that could faithfully represent economic phenomena cannot necessarily be said to be sufficient. To make this point clear, in the discussion below, "reliability" is defined as the degree to which measured value 
(representation) actually approaches the actual economic phenomenon (fundamental value) that should be represented, referring to the method in Ijiri (1968, pp. 192-195). ${ }^{1}$ The constituent elements thereof include the matter of objectivity as seen in the degree of variation $(\mathcal{V})$, even if the average values $(\bar{x})$ of the results of measurement are the same, and the issue of faithfulness as seen in the difference $(\mathcal{B})$ between the average value and the fundamental value $\left(\chi^{*}\right)$. The sum of both of these $(\mathcal{R})$ is "reliability". Accordingly, reliability $\mathcal{R}$ is the sum of objectivity $\mathcal{V}$ plus faithfulness $\mathcal{B}$ (Ochi, 2012, p. 123):

$$
\mathcal{R}=\mathcal{V}+\mathcal{B}
$$

The smaller this value, the closer the measurement is to the fundamental value. Although the concepts of reliability, objectivity, and faithfulness are very similar, they are separate concepts. The replacement by the IASB (2010) of the concept of reliability with faithful representation that degraded the positioning of verifiability to a sub-property under this framework can be understood, for example as in the case of fair value measurement, to be efforts to improve the usefulness of accounting information by increasing reliability $(\mathcal{V}+\mathcal{B}$ is smaller for (4) than for (3) in Figure 1) even though the objectivity of the measurements has decreased (distribution is larger for (4) than for (3)), due to the higher degree of faithful representation (the measurement average $\langle\bar{x}\rangle$ is closer to the fundamental value $\left\langle\mathcal{X}^{*}>\right.$ ). In addition, what IASB (2010) criticized as "an international misunderstanding of the concept of reliability" is interpreted as verifiability in the sense of accuracy in "objectivity". But reliability consists of not only objectivity but also faithfulness, as described in the next section the concept of objectivity is closely related to that of indirect verifiability, and faithfulness is closely related to direct verifiability.

(1)

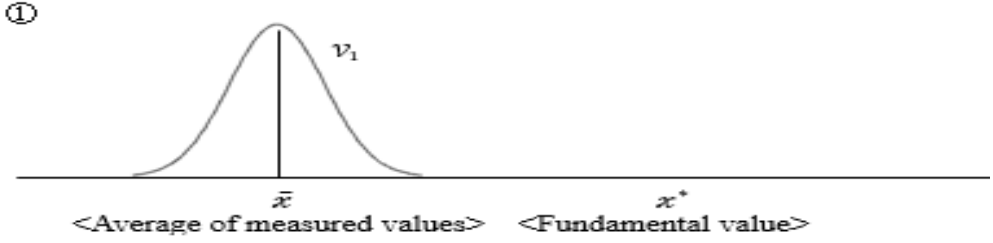

(2)

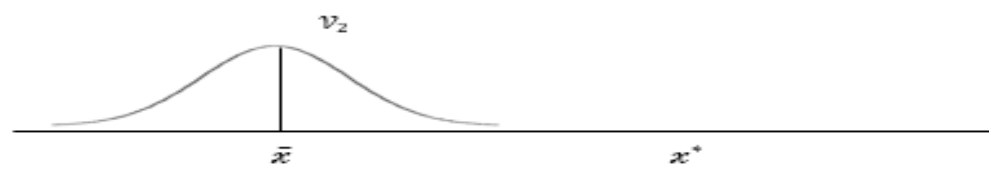

(3)

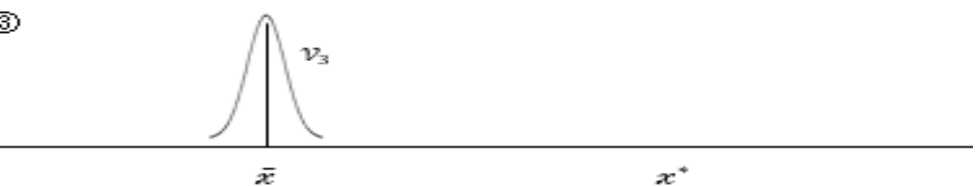

(4)

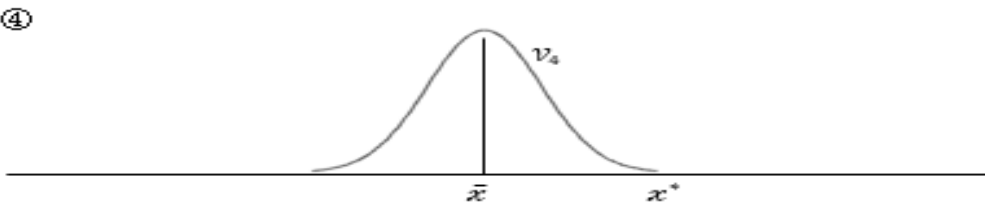

Figure 1. Relationships among reliability, objectivity, and faithfulness in accounting measurements. Source: Ochi (2012, p. 124).

\footnotetext{
${ }^{1}$ As used from FASB (1980) until the revision of IASB (2010), “reliability” concerned faithful representation of the subject being represented, and assurance for users of information was defined as securing through verification the fact that measured values had the characteristics represented (FASB, 1980, para. 59).
} 
Here, under the formularized models under Level 3 fair value measurement (for example, the option pricing model), the possibility of a broad base of the distribution corresponding to the diversity of input values (variation in measured values, (1)-(3) under Figure 1) basically is the same as for accounting estimates (e.g., allowance for doubtful accounts, defined benefit liabilities). However, in a domain in which measurement methods are not formularized, it is not only input values that may vary. Measurement frameworks themselves may vary as well, resulting in varied distributions, and in many cases there is no decisive factor for determining which expected value is close to the fundamental value (refer to (5)-(6) in Figure 2).

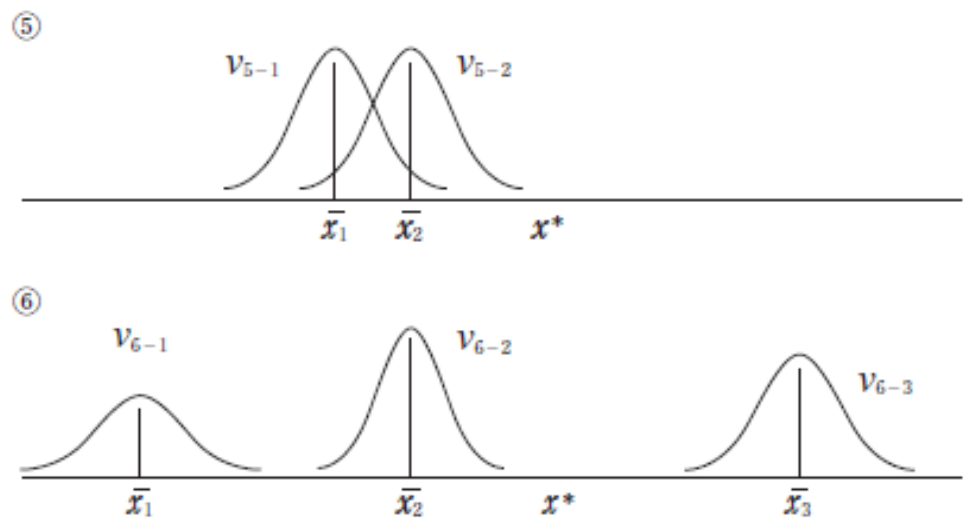

Figure 2. Diversity of distribution of measurement values and convertibility. Source: Ochi (2012, p. 124).

In this case, (1) when it is possible to converge the diversity of measurements through the distribution of repeated proximate recalculations, as actually conducted in real-estate appraisal (5) in Figure 2), it might be a good idea to entrust efforts to shrink these gaps to reliable experts such as real-estate appraisers. However, (2) when as seen in assessment of the economic value of a brand, CDOs, or unquoted equity instruments the distribution is highly scattered due to marked diversity caused by variation in measurement methods (6) in Figure 2), it is difficult even for experts to overcome such a state because fundamentally it is an issue of appraisal theory and financial engineering, and entrusting it to the judgment of management is unlikely to resolve the situation. In a domain of Level 3 fair value measurement in which important deviations will arise in the breadth of estimates due to the immaturity of measurement techniques (Ochi (2012) referred to this as "Level 4"), doubts will arise with regard to neutrality to guarantee faithful representation as well.

Such measurement issues arise due to the fact that while originally the factors causing uncertainty in measurement of fair value are identified widely as the assumptions of market participants in making pricing decisions, since this is a concept that includes not only input values but also risks of assessment techniques, in stratification of inputs classified in the fair value hierarchy of IFRS 13 (Levels 1-3) from the perspective of whether or not they are observable, such inputs are defined with a focus only on values input in assessment techniques (data) (IFRS 13, para. 73). Here, even when variation in measurement values arises due to a high degree of uncertainty about the values input to the formularized model in Level 3 financial instruments, it is possible to derive a useful measurement basis if they converge within a certain reasonable breadth (IASB, 2015, para. BC6.56), and measurement values including diversity of immature model selection, as noted above (6) under Figure 2) result in a material uncertainty on a different dimension than that of uncertainty of inputs (see Table 2). 
Table 2

Fair Value Hierarchy and Measurement Uncertainty

\begin{tabular}{|l|l|}
\hline Priority & Content of inputs \\
\hline Level 1 inputs & $\begin{array}{l}\text { Quoted prices (uncorrected) in active markets for identical assets or liabilities to } \\
\text { which the entity has access on the measurement date }\end{array}$ \\
\hline Level 2 inputs & $\begin{array}{l}\text { Directly or indirectly observable assets or liabilities included among inputs other } \\
\text { than the quoted prices included under Level } 1\end{array}$ \\
\hline $\begin{array}{l}\text { Level } 3 \text { inputs } \\
\text { Material uncertainty domains }\end{array}$ & Inputs not observable with regard to assets or liabilities \\
\hline
\end{tabular}

Note. Source: Prepared by the author based on IFRS 13.

Financial instruments for which material uncertainties in Level 3 fair value measurement (described as "Level 4" above) could be problematic include securitized instruments ${ }^{2}$ (such as collateralized debt obligations, or CDOs), unquoted equity instruments, and insurance liabilities. While it would appear that fair value measurement of insurance liabilities has been abandoned following international criticism in the IASB, IFRS 9 permits recording of profits and losses on securitized instruments through fair value measurement when the cash-flow conditions $^{3}$ are not satisfied (IFRS 9, paras. B4.1.22, B4.1.26, BC4.22, BC4.26), so that prices of similar instruments and price valuation models are used when no trading prices are available. However, in price valuation of CDOs, securitized instruments that triggered the financial crisis, the fact that valuations fluctuated widely depending on the assumptions used even under a copula model, the model used most widely as a standard manifested itself in the subprime loan problem, so that overreliance on immature models introduced significant externalities into financial and economic society. Accordingly, the assumption of correlation among collateralized assets came to be considered important and a variety of models was developed to estimate correlation, but since generally these have not yet reached the stage of being formularized valuation can vary substantially even for identical instruments depending on which model is chosen (see Table 3).

Table 3

Credit Spread Evaluation for CDOs in Each Tranche (Measurements Made Classifying Copula Models by Differences in the Shape of Interdependence among Assets; Unit: bp.)

\begin{tabular}{lcccl}
\hline Copula & Equity & Mezzanine & Senior & Super-senior \\
\hline Normal & $1,147.43$ & 63.38 & 0.65 & 0.000 \\
$t(20)$ & $1,061.07$ & 86.94 & 2.33 & 0.002 \\
$t(6)$ & 899.52 & 127.82 & 9.11 & 0.043 \\
$t(3)$ & 735.55 & 165.40 & 21.81 & 0.196 \\
Reverse Gumbel & $1,018.34$ & 59.01 & 19.04 & 2.685 \\
Clayton & 860.61 & 135.77 & 12.65 & 0.099 \\
Frank & $1,324.02$ & 15.54 & 0.00 & 0.000
\end{tabular}

Note. Source: Based on Shintani, Yamada, and Yoshiba (2010, p. 109) with some revisions.

When there is diversity in distributions and the difference among multiple expected values is important enough to affect investment decision-making, if management and other decision-makers may choose or average values at their discretion then that could not be said to increase faithfulness a priori. For example, valuation of unquoted equity instruments through hybrid valuation of other methods used for purposes such as M\&A deals

\footnotetext{
2 IFRS 9 refers to securitized instruments having a senior-sub structure as "contractually linked financial instruments".

${ }^{3}$ With regard to securitized instruments, etc., IFRS 9 called for valuation of the original instruments serving as sources of funding for repayment and the backing cash flow, based on a "look-through approach", to satisfy cash flow requirements.
} 
is a method of calculating within a certain breadth the results of valuation using each method and then deriving the ultimate valuation through consideration of matters such as overlapping among individual evaluation results. However, an assumption of this approach is that the results of each valuation method will be close. While the hybrid approach used in M\&As and other transactions is easy to apply when the results of each evaluation method are close to each other, sufficient caution is required when applying this approach in M\&A negotiations if the results of multiple evaluation methods are markedly different from each other. Probably, there is a need to think about a stricter approach to accounting measurement, which differs from measurement for trading and other purposes, in which the range of judgment and discretion is comparatively broad for decisions based on supply and demand factors, power relations, and other considerations. ${ }^{4}$

Unquoted equity instruments within the scope of IFRS 9 Financial Instruments, published in December 2012 as part of the IFRS educational initiatives, call for determining the weight of valuation results under each method when choosing an amount to best express fair value within a certain scope of valuation amounts by considering: (1) the reasonability of the scope of valuation amounts; (2) relative objectivity of inputs; and (3) individual facts and conditions (paras. 14 and 15). However, even while recognizing that there is no absolute method established for each individual approach, it is unlikely that reliable figures could result from collecting together figures that are unreliable individually through use of multiple approaches together. When accounting measurements have the nature of a diverse distribution with important differences, simply averaging these cannot be described as a faithful representation, and in fact it can be considered not to satisfy the minimum standard of reliability.

\section{Relationship between Measurement Uncertainty and Verifiability}

\section{Measurement Uncertainty in Level 3 Fair Value Measurement}

With regard to review of the conceptual framework, the IASB added the level of measurement uncertainty to the factors to consider in selecting the basis of measurement (IASB, 2015, paras. 6.55, 6.56, BC6.56). Behind this is the fact that in the 2010 revisions to the conceptual framework reliability was replaced by faithful representation as fundamental qualitative characteristics of useful accounting information, but since this point already had been the subject of strong international criticism even at the stage of the materials for discussion prior to IASB (2015) this change is understood as a proposal intended to gain the understanding of related parties by approaching the pre-2010 IASB conceptual framework through clear statement of the tradeoffs of measurement uncertainty level without changing the terminology.

When measurements include material uncertainty, then even if the uncertain nature of estimates is disclosed in the notes, it would not be possible to make up for the lack of clarity of financial performance in the financial statements themselves or major errors in measurements. IASB (2015, para. BC5.12) identified two cases of such uncertainty: (1) when the scope of possible results is extremely broad and it is very difficult to estimate the probability of each result; and (2) when measurement of resources or obligations requires an abnormally difficult distribution or a highly subjective distribution of cash flow rather than relating to the

\footnotetext{
${ }^{4}$ While the view that sees as problematic the gap with the ideal state (perfect, complete markets) of fair value measurement (the economic income concept) (e.g., Beaver, 1998), this is an issue that even at this stage has not been elucidated fully with regard to how it arises, in what cases, and the degree of a gap that is intolerable. On this point, Nissim and Penman (2008) expressed a viewpoint similar to that of this paper on the point of seeing it as one gauge for basic application of no-arbitrage price in judging the appropriateness of application of Level 3 fair value.
} 
subject of measurement alone. While broadly speaking it would be included in these cases, keeping in mind the domain of "Level 4" within Level 3 fair value measurement in financial investment, perhaps one also should be explicitly conscious of the case (3) when objective convergence of diversity of measurement distributions is difficult in connection with the immaturity of a model.

In the domain in which measurement involves material uncertainty ("Level 4"), since even if the fundamental value exists it is not possible for those conducting measurement to observe it in reality (the assumptions of market participants do not converge), it is not self-evident that faithfulness will increase through measurement values of immature models. Unobservable fair value that depends on the judgments of management under such conditions is a misuse of fair value (Kothari, Ramanna, \& Skinner, 2010, pp. 265-266), and fair value that is difficult to verify could be a hotbed for window dressing (Peasnell, 2006, p. 9). Excessive expansion of fair value measurement results in such phantom precision not present in measured values. It might contribute more to useful investment decision-making, by avoiding distortions in the reliability of measurements, if measurements in the financial statements themselves used acquisition prices and variations in the measured values among different methods of fair value measurement were disclosed in the notes, as ranges ${ }^{5}$ (Ochi, 2012, p. 129).

As noted above, the definition of fair value in IFRS 13 emphasizes that it is not a company-specific measurement as a market-based measurement, and since the assumptions used by anentity in measuring fair value are ones likely to be used by market participants in pricing the assets or liabilities under current market conditions, in theory even different companies should reach the same estimates for the same items, and thus the entity’s intentions should not be related to fair value measurement (IASB, 2015, para. 6.44). In this case:

If an entity is estimating the fair value of a specialized item, there may sometimes be little reason for the entity to assume that market participants would use assumptions different from those that the entity itself uses. In that case, measurement from a market participant perspective and measurement from the entity's perspective are likely to produce similar measures. (IASB, 2015, para. 6.33)

However, the case in which "an entity is estimating... a specialized item" is understood to be conspicuous in the domain of material uncertainty ("Level 4") within Level 3 fair value measurement above. Accordingly, the assumptions specific to the entity are fictitious under the assumptions of market participants, and even though it is only the relevant entity that makes such estimates, their peculiarity and reliability could be seen to be concealed by the fiction of the assumptions of market participants (Ochi, 2012, p. 60).

\section{Doubts about the IASB's Explanations Concerning Verifiability}

While the new way of thinking adopted by the IASB (under which measurement uncertainty is a constituent element of faithful representation) overlaps with the discussion of "Level 4" and the limits of fair value measurement in financial investment mentioned above, we would like to add the following consideration of the importance of verifiability as well.

\footnotetext{
${ }^{5}$ Even if one could suppose that there would be measurement values with higher degrees of faithfulness than acquisition prices, since it is possible that fundamental value could be overvalued depending on the method of measuring fair value chosen, it remains uncertain whether the resulting degree of faithfulness would be higher than that of acquisition price (Ochi, 2012, p. 129). With regard to fair value measurement including Level 3, doubts long have been expressed from perspectives such as that of subjectivity of inputs (e.g., AAA's Financial Accounting Standards Committee, 2007), and from the point of view that even if fair value information is useful for valuing an entity it is important to differentiate between recognizing it in financial statements themselves or in the notes, the view has been expressed that it is not necessary to identify in the financial statements fair value information including noise and reflect it in profits and losses (e.g., Ball, 2006).
} 
Reflecting in part the description in the current conceptual framework of verifiability as being useful for convincing users that the accounting information faithfully presents economic phenomena (IASB, 2010, para. QC26), ASBJ (2015) emphasized that verifiability is one of the important characteristics of financial information that increases the reliability of financial information presented in financial statements (ASBJ, 2015, para. 24). In other words, since when material measurement uncertainty arises there is a possibility that independent observers having different knowledge might not reach consensus, measurement uncertainty is related to the degree of verifiability (ASBJ, 2015, para. 19), and use of unobservable inputs (as in the case of Level 3), even when it could contribute to the provision of relevant information, could make it difficult to present the values faithfully because the degree of verifiability will decrease relatively (op. cit., para. 21).

On the other hand, IASB (2010), which degraded verifiability from one of the fundamental qualitative characteristics of accounting information, is based on the understanding that even though most of the forward-looking estimates that are extremely important to providing relevant financial information are not directly verifiable, elimination of information related to those estimates would greatly decrease the usefulness of financial information (IASB, 2010, para. BC3.36), so that even if it lacks verifiability it is not necessarily the case that information is not useful (op. cit., para. BC3.34). Since in IASB (2015), the concept of verifiability is used with a meaning that is restricted to "direct verifiability” and if observing this same terminology for ASBJ (2015), then it would be difficult to verify forward-looking financial information until the time at which it arises in the future, an understanding is indicated under which verifiability is not necessarily an essential characteristic of useful financial statements as a whole.

However, the conceptual category of verifiability under the explanation in IASB (2015) leads to questions from the following perspectives (Ochi, 2017, p. 6):

(1) (Direct) verifiability is used in a highly limited context (i.e., one close to matching verification as in inspection of cash balances), and it has been pointed out that (direct) verifiability under that limited context is not an essential characteristic of useful information. Traditionally, the definition of verifiability refers to the ability of knowledgeable independent observers to reach consensus that a certain representation is a faithful representation even if it does not match perfectly, and quantitative information does not need to be a single point estimate. Rather, it is said to refer to conditions under which the scope of conceivable amounts and related probabilities are verifiable (IASB, 2010, para. QC26). Thus, there is no need to limit direct verifiability to a perfect match ${ }^{6}$;

(2) While fair value measurement is a measurement of the current price, even in a case in which the inputs to the measurement method involve a breadth of estimates including forecasts of the results of future events, if the model is formularized then it is verifiable within a certain reasonable extent;

(3) Indirect verification as defined by the IASB is considered to refer to "recalculating the outputs using the same methodology" (IASB, 2010, para. QC26), and this is no more than "that the chosen recognition or measurement method has been applied without material error or bias” (FASB, 2006, para. S9(b)) and “does not guarantee the appropriateness of the method used” (FASB, 2006, para. QC26). Since the appropriateness of the method used is not included in the perspective of reasonable verification, and direct verifiability is used in the highly limited context noted above, some narrow gaps in information that should be covered by verifiability appear between direct and indirect verification.

\footnotetext{
${ }^{6}$ Rather than an issue of black or white, this is an issue of whether verifiability is high or low, and naturally the more the distribution of measurements is concentrated around a single point, the higher the verifiability of the figures used as measurement values of the phenomenon (FASB, 1980, para. 84). Put another way, this concerns whether the degree of consensus on measured values is high or low, and instead of perfectly matching values, a reasonable breadth is tolerable in the sense of a consensus of multiple opinions.
} 
The way of thinking concerning verifiability that involves separating it into direct verifiability and indirect verifiability has been apparent since the time of FASB (1980) (Statements of Financial Accounting Concepts: SFAC No. 2, Qualitative Characteristics of Accounting Information) ${ }^{7}$, and basically, this way of thinking is followed in the conceptual framework (IASB, 2010, para. QC27) as well. Direct verification refers to verification of accounting measurement values themselves using direct evidence (FASB, 1980, para. 87) and is understood as an issue of the faithfulness of measurements, mentioned above. Specific examples given include cash calculation and market prices of securities. While this explanation frequently evokes images that are close to that of matching verifiability, today it is more expansive than at the time of SFAC No. 2, including measurements from estimates and, in particular, fair value based on financial theory, so that it would appear that the scope of direct verifiability differs over time.

On the other hand, indirect verification is verification limited solely to the accounting procedures used (FASB, 1980, para. 87) and is understood as an issue related to the objectivity of measurement discussed earlier. In other words, it is confirmation through verifying the inputs to models, formulas, or other methods and using the same procedures to recalculate the outputs. For example, verification of inventories is conducted by checking inputs (quantities and costs) and recalculating end-of-term balances of inventories using identical cost-flow assumptions (such as FIFO) (IASB, 2010, para. QC27). In addition, for the amount of depreciation over a certain period, the depreciation method, estimate factors used, and consistently of their application from the start to the end of the period are verified (FASB, 1980, para. 87). Under this definition, it is not possible to guarantee through indirect verification whether the applicable information has a high degree of faithfulness of representation (FASB, 1980, paras. 88-89), and this leads to the understanding that indirect verifiability is not a constituent element of faithful representation, while faithful representation also may have an independent existence even in the absence of (direct) verifiability.

What must be noted here is that fair value measurement using a formularized model involves aspects that cannot be discussed on the same level under the category of indirect verifiability as measurements of book values of end-of-period inventories and depreciation in a single fiscal period. For inventories, the main focus is on how to represent in fictional terms the amount distributed to each period through a formula, bound by a certain total amount of costs. While only indirect verifiability is appropriate for such a functional distribution method, measurement of Level 3 fair value through a formularized model makes it possible to verify the rationality of whether it is a faithful representation based on a benchmark supported by a market price called a no-arbitrage price. For example, the theoretical price of an option is a portfolio reproducing the pricing process of the underlying asset and the option's payoffs under a number of market assumptions (option pricing model). When such a no-arbitrage price is available, it is possible to approach an objective value grounded in market prices.

Even though the Black-Scholes Model is based on certain assumptions, it is important to note that the quantification method has been formularized based on financial engineering guarantees, as a common scale used by market participants. While it is true that in Level 3 fair value measurement the measured values may vary with inputs based on the judgments of management under a formularized model, the same is true of estimates such as allowance for doubtful accounts. As noted above:

Verifiability means that... observers could reach consensus, although not necessarily complete agreement, that a particular depiction is a faithful representation. Quantified information need not be a single point estimate to be verifiable. A range of possible amounts and the related probabilities can also be verified. (IASB, 2010, para. QC26)

\footnotetext{
7 The terms "direct verifiability" and "indirect verifiability” themselves first came to be used starting with FASB (2006).
} 
At the same time, in the "Level 4" domain in which as noted above no model has yet been formularized, there may be material uncertainties and deviations in measured values and it is not possible to reach consensus on reasonable estimates of amounts, so that in this sense indirect verifiability is the only reasonable approach in such a domain.

\section{Reconstructing the Conceptual Categories of Verifiability}

To elaborate on the issues with IASB conceptual categories using auditing of financial statements as an example, the auditor employs the systematic approach of verifying through audit methods that include the reasonability and appropriateness of choice of methods for estimate information for which matching verifiability is not possible ${ }^{8}$. Of course, in the case of accounting measurements the significance of verifiability is focused on whether or not a particular representation can be said to be a faithful representation (faithfulness), and this is not necessarily the same as in the case of an audit, in which conformity to accounting standards (objectivity) is another gauge ${ }^{9}$. However, auditors also need to make practical judgments, and when the rationality of measurements is questioned during verification of account measurements using evidence verifiability is an issue in auditing in the same meaning as in account measurements, and verification is conducted to determine whether or not a representation is faithful.

Auditors should be able to verify the reasonableness of estimates through interval estimation of variance in measured values, and it is conceivable that conceptual classification of verifiability could cover clearly the definition of verifiability through classification into "matching verifiability" (as in inspection of cash balances ${ }^{10}$ ), "reasonable verifiability" (a concept that includes verification of the reasonableness of selection of methods ${ }^{11}$ ), and "indirect verifiability" (verification of only the application of selected methods ${ }^{12}$ ). As noted above, the IASB explains "direct verifiability" in a very narrow context (nearly "matching verifiability") ${ }^{13}$. Subdivision into the two classifications of "matching verifiability" and "reasonable verifiability" has been employed here in order to avoid rhetoric that would suggest an external view that includes the two classifications of direct and indirect verification in their entirety. In other words, "reasonable verifiability" refers to the possibility of independent knowledgeable observers reaching consensus, and this is a reconstruction of conceptual classification in accordance with the definition of verifiability by the standard setters (see Table 4).

\footnotetext{
${ }^{8}$ The International Auditing and Assurance Standards Board (IAASB) has published International Standard on Auditing (ISA) No. 540 on audit procedures for accounting estimates including fair value measurement, which demands, in order to confirm the appropriateness of a model: (1) the model's theoretical soundness and mathematical integrity, including the appropriateness of model parameters; (2) the consistency and completeness of the model's inputs with market practices; and (3) the model's output as compared to actual transactions.

${ }^{9}$ It is likely that in most cases, if inventories and depreciation were calculated based on accounting standards then that would be an issue in the domain of indirect verifiability in a measurement sense since they are fictitious values, but in an auditing sense it would be an issue of direct verifiability since they conform to accounting standards. Since such abstraction of domains in which differences in the meanings of words arise between the two does not affect the subject matter directly, this paper has discussed direct verifiability and indirect verifiability assuming domains in which both measurement and auditing are discussed within the same sphere.

10 "Matching verifiability" narrows down the verification of measurements to one point, like market price or cash balance. This is synonymous with the result of "direct verifiability" as defined by the IASB.

11 "Reasonable verifiability" is defined as independent observers with knowledge reaching an agreement on the reasonableness of the estimate, which is within the definition of "verifiability" of the standard setter. Since it is a concept including verification of rationality of method selection unlike indirect verifiability, an assurance (not 100\%, but high) of faithful representation is given.

12 "Indirect verifiability" is limited to the recalculation of outputs using the same methodology (IASB, 2010, para. QC27) and does not include the viewpoint of verifying validity and rationality of method selection, so it does not assure faithful representation.

13 "Direct verifiability" refers to verifying measurements through direct observation (e.g., inspection of cash balances) (IASB, 2010, para. QC27). The range of “direct observation” of the measurements used there is limited to "matching verifiability" as defined by the author, and it is clearly distinguished from accounting estimation (IASB, 2015, para. 2.12).
} 
Table 4

Conceptual Categories of Verifiability

\begin{tabular}{|l|l|l|l|}
\hline $\begin{array}{l}\text { Common to both the IASB and } \\
\text { this paper }\end{array}$ & Categories of the IASB & Categories of this paper & $\begin{array}{l}\text { Assurance of faithful } \\
\text { representation }\end{array}$ \\
\hline \multirow{2}{*}{$\begin{array}{l}\text { Areas covered by definitions of } \\
\text { verifiability }\end{array}$} & Direct verifiability & Matching verifiability & (Blank area) \\
\cline { 2 - 4 } & Indirect verifiability & Reasonable verifiability & O \\
\hline
\end{tabular}

Notes. The area inside the bold frame is considered to be a constituent element of faithful representation. Source: Ochi (2017, p. 10).

Auditing requires expression of an opinion at the level of reasonable assurance ${ }^{14}$, and for accounts suitable for "matching verification", it is possible to secure a very high degree of confidence through physical evidence. On the other hand, for accounts that include estimates audit procedures solidify the grounds for expressing an opinion through verification of whether these are within the range of reasonable estimates, and this is conducted through "reasonable verification" including the appropriateness of management's choice of estimation methods. At the same time, indirect verification as defined by the IASB extends no further than verification of whether the methods chosen by management are applied without bias, instead of verifying the appropriateness of the methods applied, and it needs not to be mentioned that this does not reach the level of reasonable assurance at an audit level.

While verification of Level 3 fair value measurement through auditing ("reasonable verification") can be conducted within a reasonable extent, when it includes cases involving material uncertainty in estimates, such as calculations made using unformalized methods ("Level 4"), then depending on the state of holdings of such assets they could have an impact on consideration of audit materiality as well (see Figure 3). This makes it difficult to accumulate the grounding for effective judgments by auditors ("reasonable verification"), so that only indirect verification can be employed. Under such conditions, no matter how diligently the auditors carry out audit procedures addressing material uncertainties in estimates at the level of reasonable assurance may merely invite the risk of litigation (Christensen, Glover, \& Wood, 2012, p. 140).

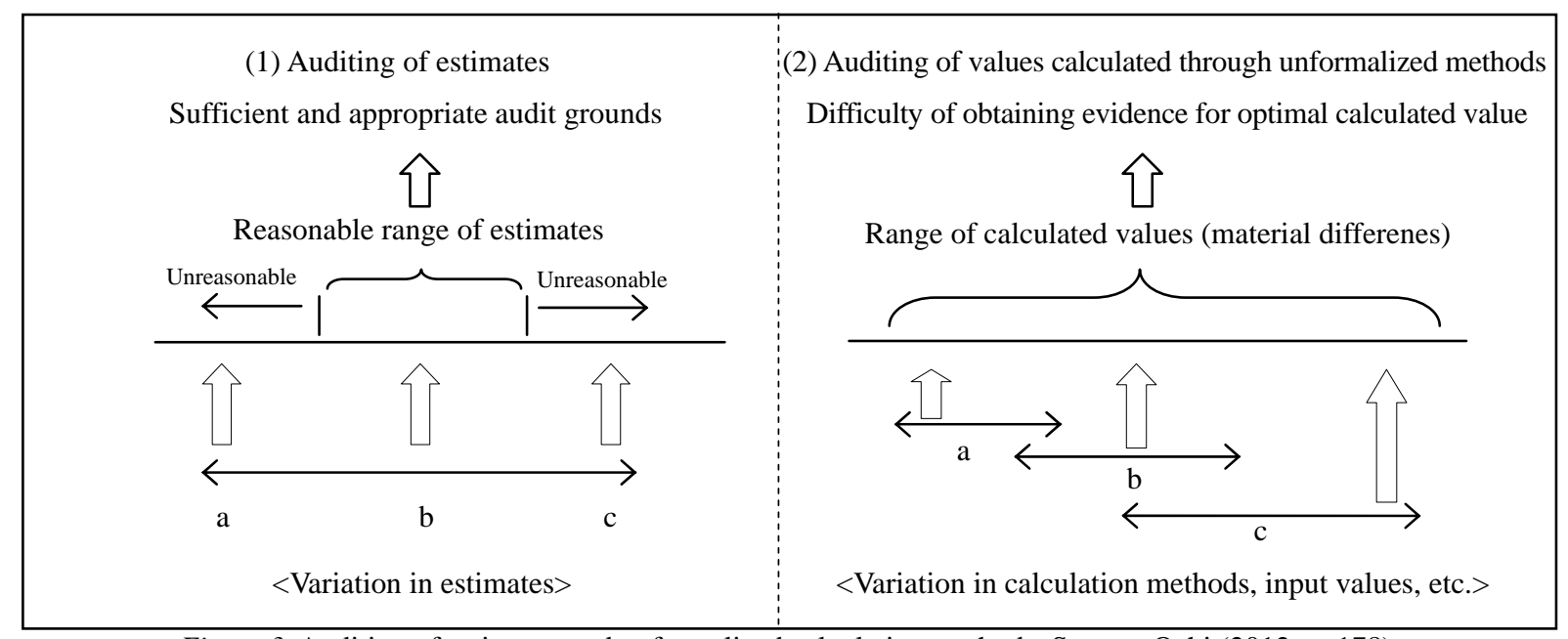

Figure 3. Auditing of estimates and unformalized calculation methods. Source: Ochi (2012, p. 178).

\footnotetext{
${ }^{14}$ According to Christensen et al. (2012, p. 137), the Big Four audit firms set confidence for appropriate presentation of financial statements at $90 \%-95 \%$.
} 
If the current broadly defined Level 3 fair value measurement (particularly "Level 4") continues to be tolerated with the function of the view of market participants (actually an entity-specific view) and the cloak of use of the models (actually unformalized in financial engineering), then it would mean that conditions in which it is difficult even to conduct reasonable verification of information (interval estimation within a reasonable extent) would remain unaddressed. If measured values lack verifiability then the danger increases that what the information seeks to represent is not in fact represented faithfully, and as a result there would be a high likelihood that users would be more cautious. Particularly since the financial crisis, which resulted from failure due to overconfidence in the utility of immature models, one probably cannot say that information for which even reasonable verification is difficult would be useful a priori. Based on the argument presented through now, even if "matching verifiability" and "reasonable verifiability" together are fundamental constituent elements of faithful representation, this would not be unnatural in any way. This can be considered to be intimately related to the lack of material uncertainties in measurements.

If we elaborate this using the relationship mentioned earlier between a measurement's faithfulness (proximity of average measurements to the fundamental value) and its objectivity (distribution of measurements) (see Figure 4), then it goes without saying that both faithfulness and objectivity would be at their greatest in a case in which "matching verifiability" narrowed to measured values at a single point, such as market prices, is appropriate. Next, in cases such as Level 2 fair value or Level 3 fair value based on a formularized model, while is assumed that there is a certain breadth of variation according to the input variables, as long as this is within a reasonable extent then independent knowledgeable observers could reach consensus on it and reasonable verifiability could be achieved. While there may be high and low levels of objectivity according to accounting estimates (variation in inputs), it reasonably can be expected that average measured values would have a higher degree of faithfulness. On the other hand, in the case of a distribution with a high degree of variation in measured values due to diversity of measurement methods, material differences in measurement not within an extent considered reasonable by independent observers would arise. As a result, it would be difficult to achieve "reasonable verification" of faithfulness, and the only way to confirm the objectivity of individual measured values would be through indirect verifiability (Ochi, 2017, p. 12).

(1) Matching verifiability Market prices

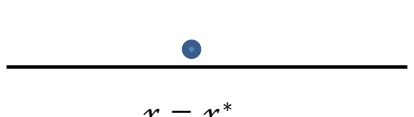

$<$ Measured value $=$ Fundamental value $>$
(2) Reasonable verifiability Formularized model

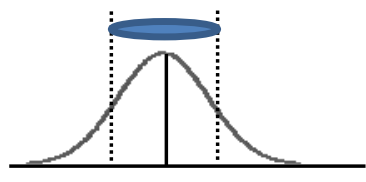

$\bar{x} x^{*}$

$<$ Measured value is close to fundamental value>
(3) Indirect verifiability

Unformalized model

?

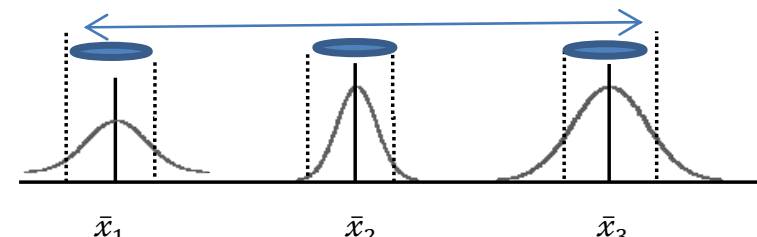

$<$ True value unclear to observers $>$

Figure 4. The relationship between verifiability, faithfulness, and objectivity (conceptual diagram). Source: Ochi (2017, p. 11). 
Major improvements in IASB (2015) include the reintroduction of the tradeoff relationship through measurement uncertainty and the fact that it considers prudence in terms of not just caution but asymmetry as well ${ }^{15}$, but as argued clearly in the past by ASBJ (2008) and others ${ }^{16}$, there is a need for reconstruction of the qualitative characteristics of accounting information in the direction of considering verifiability a fundamental constituent element of reliability and faithful representation (in a form that includes both "matching verifiability" and "reasonable verifiability"). In doing so, the deepening of discussion of verifiability between accounting measurements and auditing must not be obstructed as a matter of a different dimension. It would seem that the gaps that appear frequently between both fields may result from the problem that the concepts of verifiability and auditability are not used as common terms based on a clear consensus.

The underlying cause is the fact that under the IASB's division of verifiability into direct and indirect versions, the conceptual domain of reasonable verifiability, which should be included in the definition of verifiability, has been overlooked (whether intentionally or unconsciously). Including "matching verifiability" and "reasonable verifiability" together as fundamental constituent elements of faithful representation can be considered important from the perspective of the soundness of the accounting system, not just the passive sense of avoiding inconsistencies between accounting and auditing. That is, when accounting measurements are conducted without consideration for (reasonable) verifiability, not only are the grounds for usefulness in decision-making damaged but a gap domain arises in which although accounting judgments can be made auditing judgments cannot be made fully, and this could be a breeding ground for accounting fraud. A situation that lacks reasonable verifiability (or auditability) can be considered an irresponsible case that has gone too far from the perspective of the responsibility of standard setters, who are expected to provide to financial and economic society a robust accounting system.

The reason the IASB (2010) degraded the positioning of verifiability to a sub-property is that it is difficult for financial information including future predictive factors to be verified (directly) until the future period arrives, and if the information that is difficult to verify is excluded, then the usefulness of financial information will decline significantly. However, that argument has in mind only ex post factological verifiability (whether it agrees with the realization value at the future point), and reasonable verifiability in the preliminary stage with respect to the reasonable range of estimates (from the current point of view, whether information-based estimates deviate from the reasonable range) is not taken into consideration. If there is no material uncertainty such as "Level 4", reasonable verification within a certain range is possible, and finding reasonable verifiability does not exclude relevant information and does not reduce the usefulness of financial information.

It is as a result of emphasizing the judgment of information dominant persons that subjective and uncertain estimation is incorporated by management into financial information. However, in the case where assessment techniques are not formulated, it is impossible for the logic itself to enable selection of the technique from a market participant's perspective, and this is a significant difference from estimation of other inputs. The IASB itself also declares that "verifiability is useful for convincing users that the accounting information faithfully presents economic phenomena” (IASB, 2010, para. QC26), and conversely, "for some estimates, a high level of

\footnotetext{
15 "Verifiability" is a key information characteristic in enabling prudence to function efficiently for coordination of interests as well (Watts, 2003, p. 208; Kothari et al., 2010, pp. 255-256).

16 The ASBJ (2008) commented that the IASB's explanation that this was simply a switch in terminology was not logically sound and that retaining verifiability as one of the fundamental characteristics would help ensure reliability of investors' accounting information. JICPA (2008) also commented that verifiability provided assurance that accounting information was being presented and that it should be considered a fundamental constituent element of faithfulness of representation.
} 
measurement uncertainty may contribute to the resulting information having little relevance, even if the estimate is properly described and disclosed” (IASB, 2015, para. 5.21). As a component of faithful representation, which defines such usefulness for decision-making, the concept of reasonable verifiability is considered to play a key role (Ochi, 2017, p. 13).

\section{Conclusion}

This paper has attempted to develop a basis for the limits of Level 3 fair value measurement (the domain of "Level 4" in which material uncertainties arise) in financial investment based on IFRS and the argument over reviewing the conceptual framework, through clarification of the relationship to faithful representation and reconstruction of the conceptual classification of verifiability (clarifying the classification of "reasonable verifiability"). While the perspective of "reasonable verifiability" identified in this paper is no more than an identification of a single issue concerning selection of the grounds for measurement and the qualitative characteristics of accounting information, more active normative and empirical discussion of these points could contribute to the development of a robust accounting system integrating the fields of financial accounting and auditing.

Empirical research ${ }^{17}$ has shown that the lower the level of fair value, the lower the value relevance although value relevance is relatively higher when factors such as financial soundness and efficacy of governance systems are high $^{18}$, and that the lower the level of fair value the more likely additional disclosure concerning matters such as the efficacy of governance systems is to provide information useful to investors ${ }^{19}$. However, it must be noted here that past empirical analysis of matters such as disclosure by level in the United States (SFAS No. 157) has argued for value relevance to Level 1 and Level 2 in connection with totalized Level 3 values mainly at banks and insurers, and there is a mixture of estimates that are based on formularized models (such as the option pricing model) and those that are not.

Of course, use of reasonable estimates is an essential component of preparation of financial statements, and it is not necessarily detrimental to the usefulness of financial statements. Rather, estimates need to be disclosed appropriately. Still, as noted above even the IASB (2015) has recognized that when the level of uncertainty of estimates of fair value is very high even if it is disclosed appropriately that the figures are estimates most information based on them could not be described as a faithful representation. The core of the issue is the case of Level 3 fair value involving material uncertainty due to a lack of a formularized model ("Level 4"), and it would be desirable to employ more exhaustive analysis of value relevance by dividing Level 3 into "Level 4" and “other Level 3", based on normative and conceptual arguments.

\section{References}

AAA's Financial Accounting Standards Committee. (2007). The FASB's conceptual framework for financial reporting: A critical analysis. Accounting Horizons, 21(2), 229-238.

ASBJ. (2008). Comments on the exposure draft: "An improved conceptual framework for financial reporting: Chapter 1: The objective of financial reporting; Chapter 2: Qualitative characteristics and constraints of decision-useful financial reporting information".

\footnotetext{
17 Examples of Japanese literature surveying these overseas empirical studies in detail include Tokuga (2012) and Obinata (2012).

18 Examples include Kolev (2008), Song, Thomas, and Yi (2010), and Goh, Ng, and Yong (2015).

19 With regard to Level 3 fair value in particular, results of analysis have shown that through optional additional disclosure of information (Chung, Goh, Ng, \& Yong, 2015), or if investors can identify that the levels of efficacy of governance (Song et al., 2010) or the capital adequacy ratio, etc. (Goh et al., 2015) are high, considerable improvements in value relevance result.
} 
ASBJ. (2015). Comments on the IASB's ED conceptual framework for financial reporting.

ASBJ. (2016). ASAF Taio Sokutei: IASB Sutaffu ni yoru Taian (“ASAF measurement: A proposal by IASB staff”) (Minutes of the 344th Meeting of the Accounting Standards Board of Japan (4)-3).

Ball, R. (2006). International Financial Reporting Standards (IFRS): Pros and cons for investors. Accounting and Business Research, International Accounting Policy Forum, pp. 5-27.

Beaver, W. (1998). Financial reporting: An accounting revolution (3rd ed.). Prentice Hall.

Christensen, B., Glover, S., \& Wood, D. (2012). Extreme estimation uncertainty in fair value estimates: Implications for audit assurance. Journal of Practice \& Theory, 31(1), 127-146.

Chung, S., Goh, B., Ng, J., \& Yong, K. (2015). Voluntary fair value disclosures beyond SFAS 157's three-level estimates. Working Paper, Research Collection School of Accountancy.

FASB. (1980). Statement of financial accounting concepts No.2, Qualitative characteristics of accounting information.

FASB. (2006). Preliminary views, conceptual framework for financial reporting: Objective of financial reporting and qualitative characteristics of decision-useful financial reporting information.

Goh, B., Li, D., Ng, J., \& Yong, K. (2015). Market pricing of banks’ fair value assets reported under SFAS 157 during the 2008 economic crisis. Journal of Accounting and Public Policy, 34(2), 129-145.

IASB. (2010). Conceptual framework for financial reporting.

IASB. (2015). Exposure draft: Conceptual framework for financial reporting.

Ijiri, Y. (1968). Kaikei Sokutei no Kiso: Sugaku-Teki, keizaigaku-Teki, Kodogaku-Teki Tankyu ("Bases of accounting measurements: A mathematical, economic, and behavioral-science investigation"). Toyo Keizai.

JICPA. (2008). Comments on the exposure draft of an improved conceptual framework for financial reporting.

Kolev, K. (2008). Do investors perceive marking-to model as marking-to-myth? Early evidence from FAS 157 disclosure. Working Paper, New York University.

Kothari, S. P., Ramanna, K., \& Skinner, D. J. (2010). Implications for GAAP from an analysis of positive research in accounting. Journal of Accounting and Economics, 50(2-3), 246-286.

Nissim, D., \& Penman, S. (2008). Principles for the application of fair value accounting. CEASA (Center for Excellence in Accounting and Security Analysis) White Paper, 2, Columbia Business School.

Obinata, T. (ed.) (2012). Kinyu Kiki to Kaikei Kisei: Kosei Kachi Sokutei no Gobyu (“The financial crisis and accounting rules: The fallacy of fair value measurement”). Chuo Keizai-sha.

Ochi, N. (2012). IFRS Kosei Kachi Joho no Sokutei to Kansa: Mitsumori, Yosoku, Risuku Joho Kakudai he no Taio ("Measurement and auditing of IFRS fair value information: Responding to expansion to estimate, forecast, and risk information”). Kunimoto Shobo.

Ochi, N. (2017). Level 3 Kosei Kachi Sokutei no Juyou na Fukakujitu-Sei wo Meguru Gainen-Teki Kosatsu (“Conceptual study on the material uncertainties of Level 3 fair value measurement: Underpinning through reasonable verifiability”). Accounting Progress, 18, 1-15.

Peasnell, K. (2006). Institution-specific value. BIS Working Papers, 210.

Shintani, K., Yamada, T., \& Yoshiba, T. (2010). Kinyu Kiki ji ni okeru Shisan Kakaku Hendo no Sogo Izon Kankei: Copula ni Motozuku Hyoka ("Mutual dependencies in asset price fluctuations during a financial crisis: A copula-based assessment”). Kinyu Kenkyu, 29(3), 89-122.

Song, C., Thomas, W., \& Yi, H. (2010). Value relevance of FAS No. 157 fair value hierarchy information and the impact of corporate governance mechanisms. Accounting Review, 85(4), 1375-1410.

Tokuga, Y. (2012). Kaikei Kijun ni okeru Kongo Kaikei Moderu no Kento (“Consideration of mixed accounting models in accounting standards”). Kinyu Kenkyu, 31(3), 141-203.

Watts, R. L. (2003). Conservatism in accounting Part I: Explanations and implications. Accounting Horizons, 17(3), 207-221. 